\title{
Analysis of postoperative pregnancy outcome in 180 women with congenital uterine malformation
}

Wei Dong ${ }^{1,2}$, Yue Xia ${ }^{3}$, Li Ren ${ }^{1,2}$, Han Zhao ${ }^{1,2}$, Chun-Yan Wang ${ }^{4}$, Hui-Mei Yao ${ }^{5}$, Li-Dan Xiao,
Lei Niann ${ }^{1,2}$, Jie Zhang

${ }^{1}$ Department of Obstetrics and Gynecology, The First People's Hospital of Yunnan Province, Kunming 650032, China

${ }^{2}$ The Affiliated Hospital of Kunming University of Science and Technology, Kunming 650500, China

${ }^{3}$ Department of Gynecology, Xiamen Hospital of Traditional Chinese Medicine, Xiamen 361000, China

${ }^{4}$ Department of Gynecology, The Second People's Hospital of Baoshan City, Baoshan 678000, China

${ }^{5}$ Department of Obstetrics and Gynecology, Cangyuan Wa Autonomous County People's Hospital, Cangyuan 677400, China

${ }^{6}$ DALI University, Dali 671000, China

${ }^{7}$ Department of Gynecology, Kunming Maternal and Child Health Service Center, Kunming 650032, China

Submitted: 20 March 2019

Accepted: 18 October 2019

Arch Med Sci

DOI: https://doi.org/10.5114/aoms.2020.97281

Copyright (@ 2020 Termedia \& Banach

\section{Abstract}

Introduction: This study aims to explore the effects of combination of laparoscopy and hysteroscopy in pregnancy outcome in women diagnosed with congenital uterine malformation (CUM). The observation criteria include pregnancy rate, misdiagnosis rate, rate of spontaneous abortion and preterm birth rate.

Material and methods: A total of 180 patients with congenital uterine malformation, who were treated in our hospital from January 2015 to June 2018, were enrolled in the study. Prior to hospitalization, all the patients had neither a history of genital tract surgery nor endocrine abnormalities, chromosomal abnormalities, immune abnormalities or other factors affecting pregnancy. Furthermore, the ovarian functions were normal, and there were no factors leading to infertility in the male partners. The diagnosis was mainly based on medical history, clinical manifestations, gynecological examinations, and ultrasonography including two-dimensional and three-dimensional ultrasonography, as well as hysterosalpingogram (HSG), magnetic resonance imaging (MRI), hysteroscopy, and/or laparoscopy or surgery. Patients were diagnosed and classified according to the Buttram classification. Results: Among these 180 patients, 37 patients were diagnosed with complete septate uterus, 96 patients had sub-septate uterus, 25 patients had unicornuate uterus, 11 patients were diagnosed with bicornuate uterus, and 11 patients had didelphic uterus. The total number of preoperative pregnancies was 112, including 106 spontaneous abortions, with an abortion rate of $94.64 \%$, and 86 total postoperative pregnancies, among which spontaneous abortions occurred 11 times, with an abortion rate of $12.79 \%$. The difference was statistically significant $(p<0.05)$.

Conclusions: Uterine malformation surgery can significantly improve the reproductive prognosis in patients with CUM.

Key words: laparoscopy and hysteroscopy, congenital uterine malformation, pregnancy outcome.

\author{
Corresponding author: \\ Yun Feng \\ The First People's Hospital \\ of Yunnan Province, \\ The Affiliated Hospital \\ of Kunming University \\ of Science and Technology \\ No. 157 Jinbi Road \\ Kunming 650032 \\ Yunnan, China \\ Phone: $+860871-63638902$ \\ Fax: +86 0871-63627731 \\ E-mail: \\ fengyun_2057m@163.com
}




\section{Introduction}

Congenital uterine malformation (CUM) is one of the most common forms of genital organ dysplasia in females, and is usually caused by congenital Müllerian duct abnormities (MDAs). The AFS classification system is based on the anatomy of the female genital tract, especially the anatomy of the uterus. Uterine malformations might be classified as hypoplasia and agenesis, unicornuate, didelphys, bicornuate, septate, arcuate, and DES drug-related. This system is simple, user-friendly and clear enough. It has been successfully adopted as the main classification system for about two decades. In 2015, the Obstetrics and Gynecology Branch of the Chinese Medical Association issued a consensus among Chinese experts on the diagnosis and treatment of female genital malformations, and classified uterine malformations as rudimentary horn of uterus, T-shaped uterus, bicornuate uterus, complete septate uterus and Robert uterus [1]. The incidence of CUM has been reported to be within 0.10-10.0\% due to different diagnostic criteria, different selection of study populations, and different diagnostic techniques. It has been reported that [2-4] uterine malformation is associated with infertility, fetal loss, premature delivery, pregnancy complications, and even perinatal death $[5,6]$. However, there are different reports regarding the effects of different types of malformations on fertility, pregnancy complications and delivery outcomes. Furthermore, it remains controversial whether surgery can help to improve pregnancy outcomes $[7,8]$. The present study retrospectively analyzed the results of 180 cases of uterine malformations and the effects of surgical treatment on fertility and pregnancy outcomes, aiming to provide a basis for the clinical consultation, evaluation and treatment of uterine malformations.

\section{Material and methods}

\section{Research subjects}

A total of 180 patients with uterine malformation, who were 18-42 years old and underwent surgical treatments in the Department of Reproductive Gynecology, the First People's Hospital of Yunnan Province from January 2015 to June 2018, were enrolled in the study. Prior to hospitalization, all the patients had neither a history of genital tract surgery nor endocrine abnormalities, chromosomal abnormalities, immune abnormalities or other factors affecting pregnancy. Furthermore, their ovarian functions were normal, and there were no infertility factors in the male partners.

\section{Methods and observation criteria}

The diagnosis was mainly based on medical history, clinical manifestations, gynecological exa- minations, and ultrasonography, including twodimensional and three-dimensional ultrasonography, as well as hysterosalpingogram (HSG), magnetic resonance imaging (MRI), hysteroscopy, and/or laparoscopy or surgery. Patients were diagnosed and classified according to the Buttram classification.

\section{Statistical analysis}

SPSS 23.0 software was used for the statistical analysis of all available data. The results were expressed as means \pm standard deviations $(x \pm S D)$ or rates (\%). The difference between groups was compared by $t$-test or $\chi^{2}$ test. $P<0.05$ was considered statistically significant.

\section{Results}

A total of 180 patients with uterine malformation were included in the study. Among these patients, the numbers of patients diagnosed with sub-septate uterus, complete septate uterus, unicornuate uterus, bicornuate uterus and didelphic uterus were 96 (53.33\%), 37 (20.56\%), 25 (13.89\%), $11(6.11 \%)$, and 11 (6.11\%), respectively. Sub-septate uterus was the most common type of CUM, followed by complete septate uterus, unicornuate uterus, bicornuate uterus and didelphic uterus.

\section{Comparison of the effects of different types of uterine malformation on pregnancy outcome before surgery}

A total of 112 pregnancies were recorded in the study group before surgery, besides the pregnancy terminations caused by human factors. Among these, 106 (94.64\%) were spontaneous abortions, 94 (83.93\%) were abortions in the early pregnancy, and $12(10.71 \%)$ were abortions in the late pregnancy. There was a difference in spontaneous abortion rate among the different types of CUM, but the difference was not statistically significant $(p>0.05)$. This suggested that CUM had a relatively great influence on pregnancy outcomes, and the incidence of spontaneous abortion was the highest. The details are presented in Table I.

\section{Comparison of the effects of different types} of uterine malformation on pregnancy outcome after surgery

Phone call follow-ups were performed within 6-30 months after the surgery among these 180 hospitalized patients who underwent surgery. Most patients attended our outpatient department for review at 1-3 months after the surgery, and were evaluated according to specific conditions by B-ultrasound and hysteroscopy. The evaluation criteria were as follows: the degree of improvement of the shape of the uterine cavity, and the signs 
Table I. Comparison of different uterine malformations according to pregnancy outcomes before the operation (\%)

\begin{tabular}{|lcccccc|}
\hline Types & $\begin{array}{c}\text { Number of } \\
\text { pregnancies }\end{array}$ & $\begin{array}{c}\text { In } \\
\text { pregnancy }\end{array}$ & $\begin{array}{c}\text { Abortion in } \\
\text { early pregnancy }\end{array}$ & $\begin{array}{c}\text { Abortion in late } \\
\text { pregnancy }\end{array}$ & $\begin{array}{c}\text { Premature } \\
\text { delivery }\end{array}$ & $\begin{array}{c}\text { Full-term } \\
\text { birth }\end{array}$ \\
\hline $\begin{array}{l}\text { Incomplete } \\
\text { uterine septum }\end{array}$ & 87 & 0 & $85.19(72 / 87)$ & $11.11(9 / 87)$ & $3.70(6 / 87)$ & 0 \\
\hline $\begin{array}{l}\text { Complete } \\
\text { uterine septum }\end{array}$ & 11 & 0 & $100(11 / 11)$ & 0 & 0 & 0 \\
\hline Unicornis uterus & 9 & 0 & $80(7 / 9)$ & $20(2 / 9)$ & 0 & 0 \\
\hline Bicornis uterus & 2 & 0 & $100(2 / 2)$ & 0 & 0 & 0 \\
\hline Didelphic uterus & 3 & 0 & $80(2 / 3)$ & $20(1 / 3)$ & 0 & 0 \\
\hline
\end{tabular}

Table II. Comparison of different uterine malformations according to pregnancy outcomes after the operation (\%)

\begin{tabular}{|lcccccc|}
\hline Types & $\begin{array}{c}\text { Number of } \\
\text { pregnancies }\end{array}$ & $\begin{array}{c}\text { In } \\
\text { pregnancy }\end{array}$ & $\begin{array}{c}\text { Abortion in } \\
\text { early pregnancy }\end{array}$ & $\begin{array}{c}\text { Abortion in late } \\
\text { pregnancy }\end{array}$ & $\begin{array}{c}\text { Premature } \\
\text { delivery }\end{array}$ & $\begin{array}{c}\text { Full-term } \\
\text { birth }\end{array}$ \\
\hline $\begin{array}{l}\text { Incomplete } \\
\text { uterine septum }\end{array}$ & 54 & $\begin{array}{c}26.92 \\
(14 / 54)\end{array}$ & $13.46(7 / 54)$ & 0 & $5.76(1 / 54)$ & $53.86(32 / 54)$ \\
\hline $\begin{array}{l}\text { Complete } \\
\text { uterine septum }\end{array}$ & 10 & $50(5 / 10)$ & 0 & $10(1 / 10)$ & 0 & $40(4 / 10)$ \\
\hline Unicornis uterus & 15 & $\begin{array}{c}26.66 \\
(4 / 15)\end{array}$ & $6.66(1 / 15)$ & $6.66(1 / 15)$ & $2(2 / 15)$ & $60(7 / 15)$ \\
\hline Bicornis uterus & 4 & $12.5(1 / 4)$ & 0 & $12.5(1 / 4)$ & 0 & $87.5(2 / 4)$ \\
\hline Didelphic uterus & 3 & $50(1 / 3)$ & 0 & 0 & 0 & $50(2 / 6)$ \\
\hline
\end{tabular}

Table III. Complications during pregnancy and pregnancy outcomes among different types of uterine malformations after the operation $(n, \%)$

\begin{tabular}{|lcccccccc|}
\hline Types & $\begin{array}{c}\text { Live } \\
\text { births }\end{array}$ & $\begin{array}{c}\text { Normal } \\
\text { delivery }\end{array}$ & $\begin{array}{c}\text { Cesarean } \\
\text { section }\end{array}$ & $\begin{array}{c}\text { Abnormal } \\
\text { placental } \\
\text { position }\end{array}$ & $\begin{array}{c}\text { Abnormal } \\
\text { fetal } \\
\text { position }\end{array}$ & $\begin{array}{c}\text { Premature } \\
\text { rupture of fetal } \\
\text { membranes }\end{array}$ & $\begin{array}{c}\text { Fetal } \\
\text { distress }\end{array}$ & $\begin{array}{c}\text { Low birth } \\
\text { weight }\end{array}$ \\
\hline $\begin{array}{l}\text { Incomplete } \\
\text { uterine } \\
\text { septum }\end{array}$ & 33 & $\begin{array}{c}35.48 \\
(12 / 33)\end{array}$ & $\begin{array}{c}64.52 \\
(21 / 33)\end{array}$ & $\begin{array}{c}25.81 \\
(4 / 33)\end{array}$ & $\begin{array}{c}16.13 \\
(2 / 33)\end{array}$ & $\begin{array}{c}3.23 \\
(1 / 33)\end{array}$ & $\begin{array}{c}3.22 \\
(1 / 33)\end{array}$ & $\begin{array}{c}8.70 \\
(3 / 33)\end{array}$ \\
\hline $\begin{array}{l}\text { Complete } \\
\text { uterine } \\
\text { septum }\end{array}$ & 4 & $\begin{array}{c}40.00 \\
(2 / 4)\end{array}$ & $\begin{array}{c}60.00 \\
(2 / 4)\end{array}$ & 0 & $\begin{array}{c}20.00 \\
(1 / 4)\end{array}$ & 0 & 0 & 0 \\
\hline $\begin{array}{l}\text { Unicornis } \\
\text { uterus }\end{array}$ & 9 & $\begin{array}{c}33.33 \\
(4 / 9)\end{array}$ & $\begin{array}{c}66.66 \\
(5 / 9)\end{array}$ & 1 & 3 & 3 & 0 & 3 \\
\hline $\begin{array}{l}\text { Bicornis } \\
\text { uterus }\end{array}$ & 2 & 0 & $\begin{array}{c}100 \\
(2 / 2)\end{array}$ & 0 & 0 & 0 & 0 & 0 \\
\hline $\begin{array}{l}\text { Didelphic } \\
\text { uterus }\end{array}$ & 2 & $\begin{array}{c}33.33 \\
(1 / 2)\end{array}$ & $\begin{array}{c}66.66 \\
(1 / 2)\end{array}$ & 0 & 0 & 0 & 0 & 0 \\
\hline
\end{tabular}

of residual mediastinum and adhesion. The earliest time of pregnancy was at two months after the surgery, and the most frequent time point of pregnancy was within 6-12 months after the surgery. More than one year after the surgery, the pregnancy rate gradually decreased. During the post-surgery follow-up, there were 86 pregnancies. Among these, 25 patients $(25 / 86,29.06 \%)$ are pregnant at present. Furthermore, therewere 11 (11/86, 12.79\%) spontaneous abortions. Among these, eight (8/86, $9.30 \%$ ) abortions occurred in early pregnancy, while three $(3 / 86,3.49 \%)$ abortions occurred in late pregnancy, and premature delivery occurred three times (3/86, 3.49\%). Full-term births occurred 47 times (47/86, 54.65\%; Table II).

Among the 50 live births after the surgery, 19 infants (19/50, 38\%) were delivered by normal delivery, while 31 infants $(31 / 47,62 \%)$ were delivered by cesarean section. Furthermore, abnormal placental position, abnormal fetal position, premature rupture of fetal membranes and fetal distress occurred in five $(5 / 50,10 \%)$, six $(6 / 50,12 \%)$, four $(4 / 50,8 \%)$ and one pregnancy $(1 / 50,2 \%)$, respectively. In addition, six newborns $(6 / 50,12 \%)$ had low birth weight. These newborns' mothers might have had one or more complications during the pregnancy (Table III). 
Table IV. Pregnancy status with each type of uterine malformation prior to surgery and after surgery $(n, \%)$

\begin{tabular}{|c|c|c|c|c|c|c|c|c|}
\hline \multirow[t]{2}{*}{ Types } & \multicolumn{2}{|c|}{$\begin{array}{l}\text { Abortion in early } \\
\text { pregnancy }\end{array}$} & \multicolumn{2}{|c|}{$\begin{array}{l}\text { Abortion in late } \\
\text { pregnancy }\end{array}$} & \multicolumn{2}{|c|}{ Premature delivery } & \multicolumn{2}{|c|}{ Full-term birth } \\
\hline & Before & After & Before & After & Before & After & Before & After \\
\hline $\begin{array}{l}\text { Incomplete uterine } \\
\text { septum }\end{array}$ & $\begin{array}{c}85.19 \\
(72 / 87)\end{array}$ & $\begin{array}{l}13.46 \\
(7 / 54)\end{array}$ & $\begin{array}{l}11.11 \\
(9 / 87)\end{array}$ & 0 & $\begin{array}{c}3.70 \\
(6 / 87)\end{array}$ & 0 & 0 & $\begin{array}{l}53.86 \\
(32 / 54)\end{array}$ \\
\hline $\begin{array}{l}\text { Complete uterine } \\
\text { septum }\end{array}$ & $\begin{array}{c}100 \\
(11 / 11)\end{array}$ & 0 & 0 & $\begin{array}{c}10 \\
(1 / 10)\end{array}$ & 0 & 0 & 0 & $\begin{array}{c}40 \\
(4 / 10)\end{array}$ \\
\hline Unicornis uterus & $80(7 / 9)$ & $\begin{array}{c}6.66 \\
(1 / 15)\end{array}$ & $20(2 / 9)$ & $\begin{array}{c}6.66 \\
(1 / 15)\end{array}$ & 0 & $\begin{array}{c}2 \\
(2 / 15)\end{array}$ & 0 & $\begin{array}{c}60 \\
(7 / 15)\end{array}$ \\
\hline Bicornis uterus & $\begin{array}{l}100 \\
(2 / 2)\end{array}$ & 0 & 0 & $\begin{array}{l}12.5 \\
(1 / 4)\end{array}$ & 0 & 0 & 0 & $\begin{array}{l}87.5 \\
(2 / 4)\end{array}$ \\
\hline Didelphic uterus & $\begin{array}{c}80 \\
(2 / 3)\end{array}$ & 0 & $\begin{array}{c}20 \\
(1 / 3)\end{array}$ & 0 & 0 & 0 & 0 & $\begin{array}{c}50 \\
(2 / 6)\end{array}$ \\
\hline
\end{tabular}

Table V. Comparison of pregnancy status in the 180 cases of congenital uterine malformations before and after the operation $(n, \%)$

\begin{tabular}{|c|c|c|c|}
\hline Types & $\begin{array}{l}\text { Before the } \\
\text { operation }\end{array}$ & $\begin{array}{l}\text { After the } \\
\text { operation }\end{array}$ & $P$ \\
\hline Pregnancy & 112 & 86 & $>0.05$ \\
\hline $\begin{array}{l}\text { Abortion in early } \\
\text { pregnancy }\end{array}$ & $\begin{array}{c}94 \\
(83.93)\end{array}$ & $\begin{array}{c}8 \\
(9.30)\end{array}$ & $<0.001$ \\
\hline $\begin{array}{l}\text { Abortion in late } \\
\text { pregnancy }\end{array}$ & $\begin{array}{c}12 \\
(10.71)\end{array}$ & $\begin{array}{c}3 \\
(3.49)\end{array}$ & $>0.05$ \\
\hline $\begin{array}{l}\text { Premature } \\
\text { delivery }\end{array}$ & $\begin{array}{c}4 \\
(3.57)\end{array}$ & $\begin{array}{c}3 \\
(3.49)\end{array}$ & $>0.05$ \\
\hline Full-term birth & 0 & $\begin{array}{c}47 \\
(54.65)\end{array}$ & $<0.001$ \\
\hline In pregnancy & 0 & $\begin{array}{c}25 \\
(29.06)\end{array}$ & $<0.001$ \\
\hline
\end{tabular}

Table IV presents the pregnancy status with each type of uterine malformation before surgery and after surgery. Table $\mathrm{V}$ presents the pregnancy status of 180 patients with CUM before and after surgery. The total times of pregnancy decreased after surgery, but the difference was not statistically significant $(p>0.05)$. Furthermore, the spontaneous abortion rate in early pregnancy and the total abortion rate dramatically decreased after surgery, and the difference was statistically significant $(p<0.001)$. However, there was no significant difference in the abortion rate in late pregnancy and the rate of premature delivery after surgery $(p>0.05)$.

\section{Discussion}

Congenital uterine malformation is an abnormal development of the accessory Wolffian duct on both sides of the female genital organ during the embryonic period. This abnormal uterine structure is caused by incomplete fusion or non-fusion of the accessory Wolffian ducts on both sides, or the unilateral normal development of the acces- sory Wolffian duct together with abnormal development of the duct on the other side. CUM is a common genital malformation in female reproductive disorders. It is regarded as a high-risk factor for pregnancy when combined with pregnancy. The incidence of perinatal complications, abortion rate, premature delivery rate and dystocia rate are higher than those in normal controls, which can cause great harm to both the mothers and infants.

In the present study, the frequency of sub-septate uterus was the highest among different types of uterine abnormalities (53.33\%), followed by complete septate uterus (20.56\%) and unicornuate uterus (13.89\%). We had more experience in dealing with uterus septate. This was consistent with the previous reports $[2,9]$. The results of the present study demonstrated that the spontaneous abortion rate might reach up to $93.1 \%$ in patients with sub-septate uterus, which was similar to that reported in the literature [10]. The possible reasons might include the following: (1) Due to uterine cavity dysplasia, and the malformed uterus might affect the embryo implantation, growth and development, thus leading to infertility and abortion. (2) Insufficient blood supply in the uterine myometrium might result in increased pressure and relative cervical insufficiency, and lead to miscarriage in late pregnancy and premature rupture of the fetal membranes. Meanwhile, this might cause an abnormal fetal position and intrauterine growth retardation $[9,11]$.

At present, uterine septum resection and cold knife resection under hysteroscopy are the main methods in metroplasty. The thickness of the bottom of the uterus is $1.2-1.5 \mathrm{~cm}$ under B-mode ultrasonography monitoring $[12,13]$. Hysteroscopy combined with laparoscopy has been advocated for the treatment in long-term infertility of over two years. However, controversy remains concerning whether pregnancy outcomes could be improved after surgery. The study conducted by Zlopasa et al. [3] revealed that when compared with the outcomes 
in preoperative ones, the abortion rate in the early pregnancy and total fetal loss rate dramatically decreased in 25 female patients with mediastinal uterus who underwent mediastinal resection. Meanwhile, the study conducted by Kirk et al. [14] suggested that surgery could not change the pregnancy outcome in patients with uterine abnormalities. In the present study, the total number of pregnancies were 112 in those with uterine abnormalities before surgery. Among these, spontaneous abortion occurred 106 times, with an abortion rate of $94.64 \%$, while the total number of pregnancies was 86 after surgery, among which abortion occurred 11 times, with an abortion rate of $12.79 \%$. The pregnancy outcome of patients with CUM could be significantly improved after uterine orthodontic surgery. For patients with uterine malformations, when they have fertility requirements, it is recommended to carry out the planned pregnancy after the surgery. Among the 11 cases with abortion after surgery, seven abortions occurred within two months after surgery, and all the patients who experienced an abortion had mediastinum uterus. Thus, a second hysteroscopy examination is necessary at two months after surgery to evaluate whether the operative incision is in the proper site, and to assess the recovery of the endometrium and uterine cavity after surgery. In the present study, no uterus rupture was found after pregnancy. During surgery, the fundus of the uterus should be maintained.

Compared to cases with a normal uterus, the adverse effects on both the mother and fetus increased significantly in those with CUM. Surgery may be avoided in cases without fertility requirements. Meanwhile, for cases with fertility requirements, reasonable managements should be carried out in the planned pregnancy and post-pregnancy period, in order to avoid adverse pregnancy outcomes as far as possible. Orthodontic surgery is recommended in CUM. Furthermore, reasonable guidance should be given according to the specific conditions of patients, in order to prepare for pregnancy. Considering the particularity of CUM, proper fetal care should be taken after pregnancy to reduce uterine sensitivity, and to increase the number of healthcare visits during pregnancy, in order to conduct psychological counseling actively, to eliminate excessive tension, and to provide confidence in the smooth delivery. Although CUM and orthodontic surgery are not absolute indications for cesarean section, close observation should be carried out during labor, and indications for cesarean section should be properly relaxed to avoid adverse outcomes.

\section{Acknowledgments}

Wei Dong and Yue Xia have contributed equally to the study.

\section{Conflict of interest}

The authors declare no conflict of interest.

\section{References}

1. Chinese Medical Association Obstetrics and Gynecology Branch. A Chinese expert consensus on the diagnosis and treatment of female genital abnormalities. Chin J Obstet Gynecol 2015; 50: 729-33 [Article in Chinese].

2. Zhang Y, Zhao YY, Qiao J. Obstetric outcome of women with uterine anomalies in China. Chin Med J (Engl) 2010; 123: 418-22.

3. Zlopasa G, Skrablin S, Kalafatić D, Banović V, Lesin J. Uterine anomalies and pregnancy outcome following resectoscope metroplasty. Int J Gynaecol Obstet 2007; 8: 129-33.

4. Hua M, Odibo AO, Longman RE, Macones GA, Roehl KA, Cahill AG. Congenital uterine anomalies and adverse pregnancy outcomes. Am J Obstet Gynecol 2011; 205: 558.e1-5.

5. Chan YY, Jayaprakasan K, Zamora J, Thornton JG, RaineFenning N, Coomarasamy A. The prevalence of congenital uterine anomalies in unselected and high-risk populations: a systematic review. Hum Reprod Update 2011; 17: 761-71.

6. Grimbizis GF, Campo R; on behalf of the Scientific Committee of the Congenital Uterine Malformations (CONUTA) common ESHRE/ESGE working group: Gordts S, Brucker S, Gergolet M, Tanos V, Li TC, De Angelis C, Di Spiezio Sardo A. Clinical approach for the classification of congenital uterine malformations. Gynecol Surg 2012; 9: 119-29.

7. Venetis CA, Papadopoulos SP, Campo R, Gordts S, Tarlatzis BC, Grimbizis GF. Clinical implications of congenital uterine anomalies: a meta-analysis of comparative studies. Reprod Biomed Online 2014; 29: 665-83.

8. Acién P, Acién M. Diagnostic imaging and cataloguing of female genital malformations. Insights Imaging 2016; 7: 713-26.

9. Takami M, Aoki S, Kurasawa K, Okuda M, Takahashi T, Hirahara F. A classification of congenital uterine anomalies predicting pregnancy outcomes. Acta Obstet Gynecol Scand 2014; 93: 691-7.

10. Salim R, Regan L, Woelfer B, Backos M, Jurkovic D. A comparative study of the morphology of congenital uterine anomalies in women with and without a history of recurrent first trimester miscarriage. Hum Reprod 2003; 18: 162-6.

11. Jacquinet $A$, Millar $D$, Lehman A. Etiologies of uterine malformations. Am J Med Genet A 2016; 170: 2141-72.

12. Nouri K, Ott J, Huber JC, Fischer EM, Stögbauer L, Tempfer CB. Reproductive outcome after hysteroscopic septoplasty in patients with septate uterus - a retrospective cohort study and systematic review of the literature. Reprod Biol Endocrinol 2010; 8: 52.

13. Zafarani F, Ahmadi F, Shahrzad G. Hysterosalpingography in the assessment of congenital cervical anomalies. Int J Fertil Steril 2017; 11: 71-8.

14. Kirk EP, Chuong CJ, Coulam CB, Williams TJ. Pregnancy after metroplasty for uterine anomalies. Fertil Steril 1993; 59: 1164-8. 